\title{
Comparison of two in vitro methods for the detection of ivermectin resistance in Haemonchus contortus in sheep
}

\author{
M. URDA DOLINSKÁ*, A. KÖNIGOVÁ, M. BABJÁK, M. VÁRADY \\ Institute of Parasitology, Slovak Academy of Sciences, Hlinkova 3, 04001 Košice, Slovak Republic, \\ *E-mail: dolinska@saske.sk
}

\section{Article info}

Received September 10, 2014 Accepted December 10, 2015

\section{Summary}

Gastrointestinal parasitic nematodes in sheep cause severe economic losses. Anthelmintics are the most commonly used drugs for prophylaxis and therapy against parasitic helminths. The problem of drug resistance has developed for all commercially available anthelmintics in several genera and classes of helminths. In vitro and in vivo tests are used to detect anthelmintic resistance. Two in vitro methods (larval migration inhibition test and micromotility test) for the detection of ivermectin (IVM) resistance were compared using IVM-resistant and IVM-susceptible isolates of Haemonchus contortus. The degree of resistance for each test was expressed as a resistance factor (RF). The micromotility test was more sensitive for quantitatively measuring the degree of resistance between susceptible and resistant isolates. The RFs for this test for IVM and eprinomectin ranged from 1.00 to 108.05 and from 3.87 to 32.32 , respectively.

Keywords: anthelmintic resistance; in vitro detection; Haemonchus contortus; Ivermectin

\section{Introduction}

Resistance to anthelmintics has become a serious problem in countries with developed sheep and goat industries, especially Australia, New Zealand, South Africa, and South America (Várady et al., 2011). Macrocyclic lactones (MLs) are currently the most common group of broad-spectrum anthelmintics for the control of nematode parasites. Reports of resistance to MLs in nematodes of small ruminants, however, have increased over the last decade (Álvarez-Sanchez et al., 2006; Diez - Banos et al., 2008; Artho et al., 2007; Bartley et al., 2006; Čerňanská et al., 2006). A number of in vitro and in vivo tests have been developed for the detection of anthelmintic resistance (Taylor et al., 2002). Several in vitro tests have been described for testing the anthelmintic activity of MLs for the detection of resistance. These tests depend on an assessment of paralysis in larvae (Gill et al., 1991; Kotze et al., 2006) or of inhibited larval development (Coles et al., 1988; Hubert \& Kerboeuf, 1992; Dolinská et al., 2013). A micromotility meter has also been developed to evaluate the motility of various larval and adult nematodes as a criterion of paralysis in the absence or presence of anthelmintics, based on a quantitative measurement of motility by photo-detectors (Folz et al., 1987a). In this method, infective larvae of Haemonchus contortus and Trichostrongylus colubriformis are exposed to an anthelmintic for $24 \mathrm{~h}$ and then transferred to the micromotility meter (Folz et al., 1987b,c; Coles et al., 1989).

The present study was designed to evaluate the potential of two in vitro methods for the detection of $\mathrm{ML}$ resistance in the sheep nematode $H$. contortus. The results of the tests are compared, and the suitability of the methods for the field screening of ML resistance is discussed. 


\section{Material and Methods}

\section{Parasites isolates}

Two susceptible isolates of $H$. contortus, McMaster and ISE (MHco3), and five resistant isolates, White River (WR), CAVR, MOX23, ISE-SL, and ISE-SLI were used in this study. The susceptible ISE isolate was obtained as an inbred isolate of $\mathrm{MHCO} 3$ (Roos et al., 2004). The McMaster isolate was isolated prior to the introduction of broad-spectrum anthelmintics and is routinely used as a reference susceptible isolate in similar studies (Gill et al., 1995). WR was isolated from the field in South Africa and demonstrated resistance to IVM (30\% efficacy at $0.2 \mathrm{mg} / \mathrm{kg}$ ) and to the benzimidazoles, rafoxanide, and closantel (Van Wyk et al., 1988). CAVR is resistant to MLs and moderately resistant to the benzimidazoles (Le Jambre et al., 1995). MOX23 has been selected for 23 generations in the laboratory for moxidectin resistance (Ranjan et al., 2002). ISE-SL has been selected in the laboratory for IVM resistance (Coles et al., 2005). ISE-SLI, derived from ISE-SL, was selected further in our laboratory using $1.5 \times$ the recommended dose of IVM.

\section{Trial design}

All isolates had been routinely maintained by passage through individually housed, helminth-naive, 5-6 month-old lambs. The lambs were infected orally with 5000 third-stage (L3) larvae of each isolate. Faecal samples were collected 35-50 days after experimental infection, and coprocultures were subsequently prepared by the method described by Henriksen and Korsholm (1983). L3 larvae were isolated from the faecal cultures by standard Baermann filtration and stored at $10^{\circ} \mathrm{C}$ in distilled water prior to use. The larvae were tested within one month after collection.

\section{Larval migration inhibition test (LMIT)}

The LMIT was performed as described by Kotze et al. (2006) in 96well microtiter plates (Millipore, Australia). Stock drug solutions of IVM (10 mg/ml in DMSO) were serially diluted 2-fold, $0.5 \mu$ l of each dilution were added to the wells of drug plates, followed by $20 \mu \mathrm{l}$ of distilled water and $30 \mu \mathrm{l}$ of a solution containing infective L3 larvae
(55 - 60 larvae mixed with amphotericin B - $250 \mathrm{mg} / \mathrm{ml}$ ). The plates were placed into plastic bags and incubated for $24 \mathrm{~h}$ at $27^{\circ} \mathrm{C}$. Rinse plates were prepared at the same time and in the same format as their corresponding drug plates. The culture medium comprised $4.75 \mu \mathrm{l}$ of each drug dilution and $400 \mu \mathrm{l}$ of distilled water. These plates were kept at room temperature. Agar/filter plates were also prepared on the same day: $75 \mu$ l of agar $(0.125 \%)$ were added to the $20-\mu \mathrm{m}$ filter of each well, and the plates were stored at room temperature. The following day, $325 \mu$ l of the solution from the rinse plate were added to the corresponding well of a plate, and the agar/ filter plate was lowered into this plate and was incubated several hours at $27{ }^{\circ} \mathrm{C}$. Twenty-four hours after the establishment of the drug plates, the worms from the drug plates were transferred to the agar/filter plates at the corresponding positions. The remaining worms in the drug plates were collected by adding $50 \mu$ l of the corresponding solution from the rinse plates to the drug plates, mixed, and then added to the agar/filter plates. The total content of each well consisted of $325 \mu \mathrm{l}$ of solution from the rinse plates, $75 \mu \mathrm{l}$ of $0.125 \%$ agar, $50 \mu \mathrm{l}$ of $\mathrm{L} 3$ larvae from the drug plates, and $50 \mu \mathrm{l}$ of the solution from the rinse plates. The prepared plates were placed into clear plastic bags and incubated under a light at $27^{\circ} \mathrm{C}$ for $48 \mathrm{~h}$. The filters were then removed, and all worms were counted.

\section{Micromotility test}

The micromotility test was performed as described by Folz et al. (1987). Movement of the larvae caused a variation in light rays refracting from the meniscus, and consequently a variation in the electrical signal produced by a photo-detector located at the level of the meniscus. The numerical representation of the modulated signal is termed the motility index. $H$. contortus L3 larvae were mixed with water $(500 \mathrm{~L} 3 / \mathrm{ml})$. A stock solution was prepared by dissolving $1 \mathrm{mg}$ of anthelmintic (IVM or eprinomectin) in a mixture of $200 \mu \mathrm{l}$ of acetone and $50 \mu \mathrm{l}$ of Tween 20 and then adding $750 \mu$ of distilled water. An identical blank solution but with distilled water replacing the anthelmintic was also prepared. L3 larvae were exposed to anthelmintic in four concentrations: 0.1, 1.0, 10.0, and $100.0 \mu \mathrm{g} / \mathrm{ml}$. Eprinomectin at the tested concentrations was less effective than IVM against all isolates, so we increased its

Table 1. Origin and status of anthelmintic susceptibility (S) or resistance (R) of ISE, McMaster, ISE-SL, ISE-SLI, MOX-23, WR and CAVR isolates of Haemonchus contortus

\begin{tabular}{llll}
\hline Isolate & R/S & Reference & Origin \\
\hline ISE & susceptible & Roos et al. (2004) & Kenya \\
McMaster & susceptible & CSIRO, Armidale & Australia \\
ISE-SL & IVM & Coles (2005) & Great Britain \\
ISE-SLI & IVM & Coles (2005) & Great Britain \\
MOX-23 & IVM & Prichard et al. (2002) & Canada \\
WR & BZ, CLO, IVM, RAF & Van Wyk and Malan (1988) & South Africa \\
CAVR & IVM, BZ & LeJambre et al. (1995) & Australia \\
\hline
\end{tabular}

BZ, benzimidazole; CLO, closantel; IVM, ivermectin; RAF, rafoxanide 
Table 2. Arithmetic mean $\pm \mathrm{SD}$ of $\mathrm{LD}_{50}$ and $\mathrm{LD}_{99}$ for susceptible and resistant isolates obtained in the larval migration inhibition test with ivermectin

\begin{tabular}{lcc}
\hline Isolate & $\mathrm{LD}_{50}(\boldsymbol{\mu} \mathbf{g} / \mathrm{ml}) \pm \mathrm{SD}$ & $\mathrm{LD}_{99}(\boldsymbol{\mu} \mathbf{g} / \mathbf{m l}) \pm \mathrm{SD}$ \\
\hline McMaster & $1.03 \pm 0.72$ & $2.80 \pm 0.61$ \\
ISE & $1.25 \pm 0.48$ & $3.00 \pm 1.24$ \\
MOX23 & $2.13 \pm 1.77$ & $34.36 \pm 25.14$ \\
CAVR & $2.80 \pm 0.72$ & $20.10 \pm 12.12$ \\
WR & $3.80 \pm 0.35$ & $8.77 \pm 4.92$ \\
ISE-SL & $3.65 \pm 0.48$ & $48.18 \pm 57.59$ \\
ISE-SLI & $5.05 \pm 1.98$ & $22.87 \pm 7.45$
\end{tabular}

concentration to $300 \mu \mathrm{g} / \mathrm{ml}$ to obtain reductions in motility. Two susceptible and four resistant isolates of $H$. contortus were tested. For each drug to be tested, $450 \mu$ l of the suspension containing $H$. contortus larvae and $50 \mu \mathrm{l}$ of the acetone/drug solutions at the four concentrations or the blank solution were added to culture tubes $(10 \times 75 \mathrm{~mm})$. The culture tubes were covered with parafilm to prevent evaporation. The tubes were incubated at $8-12^{\circ} \mathrm{C}$ for $24 \mathrm{~h}$, and the worms were then processed with the micromotility meter.

\section{Data analysis}

Motility indexes for the larval micromotility test were transformed to percent reductions of motility by the formula: [(vehicle control index - treatment index)/(vehicle control index - background index)] $\times 100$. The results are presented as a resistance factor: the ratio of the $L D_{50}$ or $L D_{99}$ for the resistant strain to the $L D_{50}$ or $L D_{99}$ for the susceptible strain. The $L_{50}$ and $L D_{99}$ values were determined by a logistic regression model (Dobson et al., 1987).

\section{Results}

Larval migration inhibition test

The results of the LMIT for IVM resistance are shown in Table 2. The $L D_{50}$ values of the resistant strains differed from those of the susceptible strains by an RF from 1.7 to 4.9 , and the $L_{99}$ values differed by an RF from 2.9 to 17.2 (Table 3 ). The $L_{99}$ values were more variable, producing a higher coefficient of variation. The mean RFs for the LMIA are shown in Table 3. The $L D_{99}$ data were better able to distinguish between the susceptible and resistant isolates.

\section{Micromotility test}

The mean reduction in motility and the $\mathrm{LD}_{50}$ values for the susceptible and resistant isolates of $H$. contortus after treatment with IVM and eprinomectin are presented in Tables 4 and 5. An IVM concentration of $10 \mu \mathrm{g} / \mathrm{ml}$ (Table 4) significantly reduced the larval motility of the susceptible $H$. contortus isolates, but only the treatment with $100 \mu \mathrm{g} / \mathrm{ml}$ IVM substantially reduced motility in the resistant isolates. The sensitive isolates displayed higher susceptibilities to the drugs tested, as indicated by the $\mathrm{LD}_{50}$ values.

\section{Discussion}

The values of RFs in LMIT in our study were as high as 12.2 for MOX-23 and 7.17 for CAVR. Kotze et al. (2006) with identical test obtained RFs for CAVR and MOX-23 of 1.7 and 5.7, respectively. LMIT utilize the ability of larvae to migrate through a filter mesh.

Table 3. Resistance factors for ivermectin (IVM) in the larval migration inhibition test

\begin{tabular}{|c|c|c|}
\hline Strains & $\begin{array}{l}\text { IVM } \\
\mathrm{RF}_{50}\end{array}$ & $\begin{array}{l}\text { IVM } \\
\mathrm{RF}_{99}\end{array}$ \\
\hline WR/McM & 3.68 & 3.13 \\
\hline CAVR/McM & 2.71 & 7.17 \\
\hline MOX23/McM & 2.06 & 12.27 \\
\hline ISE-SL/McM & 3.54 & 17.20 \\
\hline ISE-SLI/McM & 4.90 & 8.16 \\
\hline WR/ISE & 3.04 & 2.92 \\
\hline CAVR/ISE & 2.24 & 6.70 \\
\hline MOX23/ISE & 1.70 & 11.45 \\
\hline ISE-SL/ISE & 2.92 & 16.06 \\
\hline ISE-SLI/ISE & 4.04 & 7.62 \\
\hline
\end{tabular}


Table 4. Mean reduction (\%) in motility of $L 3$ larvae of resistant and susceptible strains of $H$. contortus after incubation in different concentrations of ivermectin (IVM)

\begin{tabular}{lccccc}
\hline \multicolumn{7}{c}{ Concentration of IVM $(\boldsymbol{\mu} \mathbf{g} / \mathbf{m l})$} \\
\hline Isolate & $\mathbf{0 . 1}$ & $\mathbf{1}$ & $\mathbf{1 0}$ & $\mathbf{1 0 0}$ & $\mathbf{L D}_{50}$ \\
\hline WR & 0 & 0 & 26.2 & 49.7 & 90.76 \\
CAVR & 0 & 55.2 & 52.8 & 76.1 & 4.2 \\
McMaster & 0 & 39.7 & 88.9 & 80.9 & 1.57 \\
ISE & 0 & 59.3 & 97.8 & 91.4 & 0.84 \\
MOX23 & 13.7 & 41.2 & 78.9 & 96.4 & 1.57 \\
ISE SL & 11.2 & 32 & 6.7 & 80.5 & 78.33 \\
\hline
\end{tabular}

A layer of $0.125 \%$ agar is applied to the filter mesh to create an additional barrier for the migrating larvae. The test was able to detect a level of resistance of $10 \%$ in a population. Kotze et al. (2006) detected resistance to MLs in $H$. contortus but not in $T$. colubriformis and Ostertagia circumcincta. Despite the potential of LMITs, the tests present some difficulties. Several factors may contribute to poor sensitivity. In mixed field parasitic populations, IVM may have different potencies against different species of gastro-intestinal parasites. The LMIT is suitable only for $\mathrm{H}$. contortus, which seriously limits the utility of this test for monitoring resistance in field surveys. The RFs obtained by LMITs are significantly lower than those obtained by larval development tests (Dolinská et al., 2012, 2013), which may indicate a lower sensitivity of the LMIT for the detection of IVM-resistant parasites. Additionally the cost of the microtiter plates (Millipore), in which the LMIT is performed, is considerable. From a practical point of view, the test cannot thus be used for the detection of IVM resistance in mixed populations of trichostrongylids.

Calculation of $L_{99}$ values in the in vitro tests can significantly increase test sensitivity and identify resistance when only a small proportion of the worm population is resistant (Várady et al., 2007). Based on our data from LMIT the RF99 values obtained from CAVR, MOX23, ISE-SL and ISE-SLI isolates were 1.6 - 6.7 times higher compare to RF50. Only $L_{99}$ values from WR isolate were almost identical with $L_{50}$ values. The possible reason for this could be the different proportion of resistant individuals in the isolates. While CAVR, MOX23, ISE-SL and ISE-SLI isolates showed high resistance in vivo, WR isolated from the field in South Africa demonstrated moderate resistance to IVM.
In our study the micromotility meter was used to evaluate the effect of two $M L$ anthelmintics on the motility of $H$. contortus $L 3$ larvae. Paralysis tests described previously by Martin and Le Jambre (1979), Barton (1983), and Geerts et al. (1989) were based on visual evaluations of larval paralysis, which is considered to be subjective and not sufficiently reproducible. By using a micromotility meter, the degree of subjectivity (assessing whether a larva is in motion) can be minimized. The micromotility meter has been described as a sensitive tool for measuring the in vitro motility of larval and adult H. contortus and T. colubriformis (Bennett and Pax, 1986; Folz et al., 1987b, c). Some studies, however, have demonstrated a lower ability to distinguish between susceptible and resistant isolates of H. contortus (Coles et al., 1989; Várady \& Čorba, 1998).

In the current study, the RFs ranged from 1.00 to 108.05 for IVM and from 3.87 to 32.32 for eprinomectin. Similarly high RFs (maximum 88.51-345.6) were obtained by Demeler (2005) in a comparison of the motilities of susceptible and resistant adult $T$. colubriformis and 0 . circumcincta. The use of adult parasites, however, requires the sacrifice of animals and so is not financially practical for field surveys. Our micromotility testing provided relatively high RFs, indicating a good ability to differentiate between IVM-resistant and -susceptible strains of $H$. contortus. The ability to measure the motility of larvae in mixed infections of gastrointestinal parasites, however, is questionable, because different species of gastrointestinal nematodes have different motilities, e.g. the motility of $\mathrm{H}$. contortus is much higher initially but is markedly lower after about 10 minutes (Gill et al., 1995). The present version of the micromotility test is thus unsuitable for measuring levels of resistance under field conditions.

Table 5. Mean reduction (\%) in motility of L3 larvae of resistant and susceptible strains of $H$. contortus after incubation in different concentrations of eprinomectin (EPM)

\begin{tabular}{lccccccc}
\hline \multicolumn{7}{c}{ Concentration of EPM $(\mu \mathrm{g} / \mathrm{ml})$} \\
\hline Isolate & 0.1 & 1 & 10 & 100 & 200 & 300 & LD $_{50}$ \\
\hline WR & & 43.4 & 43.4 & 53.3 & 72.2 & 71.7 & 41.04 \\
CAVR & 35 & & 49.48 & 29.3 & 65.3 & 64.7 & 49.77 \\
McM & 0 & 37.1 & 76.4 & 63.9 & 100 & 100 & 3.98 \\
ISE & 34.6 & 53.23 & 65.2 & 69.3 & 100 & 100 & 1.54 \\
MOX23 & 15.8 & 27.7 & 40.3 & 70.7 & 100 & 100 & 15.4 \\
ISE SL & 14.26 & 11.65 & 68.5 & 50.16 & 45.1 & 66.9 & 47.27 \\
\hline
\end{tabular}


Table 6. Resistance factors for ivermectin (IVM) and eprinomectin (EPM) in the micromotility test

\begin{tabular}{ccc}
\hline \multirow{2}{*}{ Strains } & IVM & EPM \\
& $\mathrm{RF}_{50}$ & $\mathrm{RF}_{50}$ \\
\hline WR/McM & 57.81 & 10.31 \\
CAVR/McM & 2.67 & 12.50 \\
MOX23/McM & 1.00 & 3.87 \\
ISE-SL/McM & 49.89 & 11.88 \\
WR/ISE & 108.05 & 26.65 \\
CAVR/ISE & 5.00 & 32.32 \\
MOX23/ISE & 1.87 & 10.00 \\
ISE-SL/ISE & 93.25 & 30.69 \\
\hline
\end{tabular}

As it was demonstrated in the previous studies, the use of avermectin analogs (eprinomectin, ivermectin aglycone) significantly increased the ability of the in vitro tests to differentiate between IVM-resistant and -susceptible isolates (Dolinská et al., 2013). These analogues produce $2-3$ times higher RR compared to IVM, which was not a case of our study in MMT. The reason for this is unclear and could be related to the motility cycles of the larvae. After incubation in the dark at $25^{\circ} \mathrm{C}$, the L3 larvae of $\mathrm{H}$. contortus were stimulated to move in a rapid sinusoidal motion by exposure to light. They then remain active for at least 10 minutes and maximum activity was reached after a short lag time of $1-2 \mathrm{~min}$. Thus $\mathrm{LD}_{50}$ values were more dependent on exposure of $\mathrm{L} 3$ larvae to the light and not the length of incubation.

The lowest RR obtained for MOX23 isolate in both tests suggested different or additional genetic mechanism in MOX resistance compared to IVM resistance. IVM is $>130$-fold more potent than moxidectin at inhibiting pharyngeal pumping (and thus blocking feeding) in Caenorhabditis elegans, and IVM initially stimulates motility before paralyzing this nematode. Moxidectin appears to only cause paralysis (Ardelli et al., 2009). Additionally slightly higher RR (especially for $\mathrm{LD}_{99}$ ) obtained in LMIT suggest that LMIT may be a superior tool to monitor resistance to MOX.

The potential of the two tests for use in monitoring IVM resistance is questionable and additional experimental work is require optimizing the test in field condition.

\section{Acknowledgements}

This study was supported by Slovak Research and Development Agency project No. APVV 0539-10 and by the project "INFEKTZOON - Centre of Excellence for Animal Infections and Zoonoses (ITMS-26220120002)".

\section{References}

Álvarez - Sánchez, M.A., Pérez - García, J., Cruz - Rojo, M.A.,
Rojo VÁZQuez, F.A. (2006): Anthelmintic resistance in trichostrongylid nematodes of sheep farms in Northwest Spain. Parasitol. Res., 99(1): 78 - 83. DOI: 10.1007/s00436-006-0130-2

Ardelli, B.F., StitT, L.E., TompKins, J.B., Prichard, R.K. (2009): A comparison of the effects of ivermectin and moxidectin on the nematode Caenorhabditis elegans. Vet. Parasitol., 165(1-2): 96 108. DOI: $10.1016 /$ j.vetpar.2009.06.043

Artho, R., Schnyder, M., Kohler, L., Torgerson, P.R., Hertzberg, H. (2007): Avermectin - resistance in gastrointestinal nematodes of Boer goats and Dorper sheep in Switzerland. Vet. Parasitol., 144(1-2): 68 - 73. DOI: 10.1016/j.vetpar.2006.09.032

Bartley, D.J., Donnan, A.A., Jackson, E., Sargison, N., Mitchell, G.B.B., JACKSON, F. (2006): A small scale survey of ivermectin resistance in sheep nematodes using the faecal egg count reduction test on samples collected from Scottish sheep. Vet. Parasitol., 137(1-2): 112 - 118. DOI: 10.1016/j.vetpar.2005.12.014

BARTON, N. J. (1983): Development of anthelmintic resistance in nematodes from sheep in Australia subjected to different treatment frequencies. Int. J. Parasitol., 13(2): 125 - 132. DOI: 10.1016/0020-7519(83)90002-4

BenNetT, J.L., PAX, R.A. (1986): Micromotility meter: an instrument designed to evaluate the action of drugs on motility of larval and adult nematodes. Parasitology, 93(Pt 2): 341 - 346

Coles, G.C., TRitschler II, J.P., LASTE, N.J., SChmidt, A.L. (1988): Larval development test for detection of anthelmintic resistant nematodes. Res. Vet. Sci., 45(1): $50-53$

Coles, G.C., Folz, D., TRITSCHLER, I.J.P. (1989): Motility response of levamisole/benzimidazole-resistant Haemonchus contortus larvae. Vet. Parasitol., 31(3-4): $253-257$

Coles, G.C., Rhodes, A.C., Wolstenholme, A.J. (2005): Rapid selection for ivermectin resistance in Haemonchus contortus. Vet. Parasitol., 129(3-4):345-347. DOI: 10.1016/j.vetpar.2005.02.002 ČERÑANSKÁ, D., VÁrady, M., ČoRBA, J. (2006): A survey of anthelmintic resistance in nematode parasites of sheep in the Slovak Republic. Vet. Parasitol., 135(1): 39 - 45. DOI: 10.1016/j.vetpar.2005.09.001 
Demeler, J. (2005): The physiological site of action and the site of resistance to the macrocyclic lactone anthelmintics in sheep parasitic trichostrongyloid nematodes. PhD Thesis, Hannover, Germany: Tierärztliche Hochschule Hannover

Diez - Banos, P., Pedreira, J., Sanchez - Andrade, R., Francisco, I., Suarez, J.L., Diaz, P., Panadero, R., Arias, M., Painceira, A., Paz -Silva, A., Morrondo, P. (2008): Field evaluation for anthelmintic - resistant ovine gastrointestinal nematodes by in vitro and in vivo assays. J. Parasitol., 94(4): 925 - 928. DOI: http://dx.doi. org/10.1645/GE-1366.1

Dobson, R.J., Griffiths, D.A., Donald, A.D., Waller, P.J. (1987): A genetic model describing the evolution of levamisole resistance in Trichostrongylus colubriformis, a nematode parasite of sheep. IMA J. Math. Appl. Med. Biol., 4(4): 279 - 293. DOI: 10.1093/ imammb/4.4.279

Dolinská, M., Königová, A., VÁrady, M. (2012): Is the micro-agar larval development $t$ test reliable enough to detect ivermectin resistance? Parasitol. Res., 111(5): 2201 - 2204. DOI: 10.1007/ s00436-012-2944-4

Dolinská, M., Königová, A., Letková, V., Molnár, L., VÁrady, M. (2013): Detection of ivermectin resistance by a larval development test - Back to the past or a step forward? Vet. Parasitol., 198(12):154 - 158. DOI: 10.1016/j.vetpar.2013.07.043

Folz, S.D., Pax, R.A., Thomas, E.M., Bennett, J.L., Lee, B.L., CondER, G.A. (1987): Detecting in vitro anthelmintic effects with a micromotility meter. Vet. Parasitol., 24(3-4): 41 - 250

Folz, D., Pax, R.A., Thomas, E.M., Bennett, J.L., Lee, B.L., Conder G.A. (1987b): Development and validation of an in vitro Trichostrongylus colubriformis motility assay. Int. J. Parasitol., 17(8): $1441-1444$

Folz, S.D., Pax, R.A., Thomas, E.M., Bennett, J.L., Lee, B.L., CondER, G.A. (1987c): Motility responses of benzimidazole-resistant Haemonchus contortus larvae to several anthelmintics. Proc. Helminthol. Soc. Wash., 54(2): $249-253$

Geerts, S., Brandt, J., Borgsteede, F.H., Van Loon, H. (1989): Reliability and reproducibility of the larval paralysis test as an in vitro method for the detection of anthelmintic resistance of nematodes against levamisole and morantel tartrate. Vet. Parasitol., 30(3): $223-232$

Gill, J.H., Redwin, J.M., Van Wyk, J.A., LaceY, E. (1991): Detection of resistance to ivermectin in Haemonchus contortus. Int. J. Parasitol., 21(7): 771 - 776: DOI: 10.1016/0020-7519(91)90144-V HenRIKSen, S.A., Korsholm, H. (1983): A method for culture and recovery of gastrointestinal strongyle larvae. Nord. Vet. Med., 35(11): $429-430$

Hubert, J., Kerboeuf, D. (1992): A microlarval development assay for the detection of anthelmintic resistance in sheep nematodes. Vet. Rec., 130(20): $442-446$

KotZe, A.C., Le Jambre, L.F., O'grady, J. (2006): A modified larval migration assay for detection of resistance to macrocyclic lactones in Haemonchus contortus, and drug screening with Trichostrongylidae parasites. Vet. Parasitol., 137(3-4): 294 - 305. DOI: 10.1016/j. vetpar.2006.01.017

Le JAMBRE, L.F., Gill, J.H., LenANE, I.J., LACEY, E. (1995): Characterisation of an avermectin resistant strain of Australian Haemonchus contortus. Int. J. Parasitol., 25(6): 691 - 698. DOI: 10.1016/00207519(94)00200-8

Martin, P.J., Le Jambre, L.F. (1979): Larval paralysis test as an in vitro assay of levamisole and morantel tartrate resistance in Ostertagia. Vet. Sci. Commun., 3(1): 159 - 164. DOI: 10.1007/ BF02268963

Ranjan, S., Wang, G.T., HiRschlein, C., Simkins, K.L. (2002): Selection for resistance to macrocyclic lactones by Haemonchus contortus in sheep. Vet. Parasitol., 103(1-2): 109 - 117. DOI: 10.1016/ S0304-4017(01)00551-9

Roos, M.H., Otsen, M., Hoekstra, R., Veenstra, J.G., Lenstra, J.A. (2004): Genetic analysis of inbreeding of two strains of the parasitic nematode Haemonchus contortus. Int. J. Parasitol., 34(1): 109 - 115. DOI: 10.1016/j.jpara.2003.10.002

TAYlor, M.A., Hunt, K.R., Goodyear, K.L. (2002): Anthelmintic resistance detection methods. Vet. Parasitol., 103(3): 183 - 194. DOI: 10.1016/S0304-4017(01)00604-5

VAN WYK, J.A., MaLAN, F.S. (1988): Resistance of field strains of Haemonchus contortus to ivermectin, closantel, rafoxanide and benzimidazoles in South Africa. Vet. Rec., 123(9): 226 - 228

VÁRADY, M., ČORBA, J. (1998): Methods of detection of anthelmintic resistance in nematodes of domestic animals. Vet. Med., 43: 347 $-354$

VÁrady, M., Čudeková, P., Čorba, J. (2007): In vitro detection of benzimidazole resistance in Haemonchus contortus: Egg hatch test versus larval development. Vet. Parasitol.,, 149(1): 104 - 110. DOI: 10.1016/j.vetpar.2007.07.011

Várady, M., Papadopoulos, E., Dolinská, M., Königová, A. (2011): Anthelmintic resistance in parasites of small ruminants: sheep versus goats. Helminthologia, 48(3): 137 - 144. DOI: 10.2478/ s11687-011-0021-7 